\title{
MEDICAL ASPECTS OF THE SPECIAL AIR SERVICE
}

\author{
Major K. HEDGES, M.Sc., M.B., Ch.B., D.T.M.\&H., D.I.H., R.A.M.C. \\ Headquarters, 3rd Division, Bulford Camp
}

SUMMARY: The historical development of the Special Air Service (S.A.S.) is traced from its inception during World War II. A particular type of soldier is required for the work undertaken by this unit of the British Army and the present day selection and training procedures of these men are discussed.

Problems of particular concern to the S.A.S. are those of prolonged isolation and combat survival in addition to more tangible health hazards.

A comparison is made between the sickness experience of the S.A.S. with that of the British Army as a whole. Because S.A.S. are geared to operate in small groups of four men, the emphasis is not so much upon the difference of sickness experience as upon the different management required for the ill and injured until such time as conventional medical help may be made available.

Medical training within the S.A.S. evolved to meet the varying needs of particular theatres of combat. Normal principles of military preventive medicine are stressed and the concept of a specially trained medical auxiliary introduced. The training and deployment of the auxiliaries, known as "Medical Aides", is the responsibility of the Commanding Officer of the S.A.S.

A contrast is made with the training of Medical Aidmen of the United States Special Forces. The most striking distinctions are in the educational background of the trainees and the training facilities available to them. Training objectives for S.A.S. "Medical Aides" are given.

Modern strategy recognises the essential requirement of the Military, as a matter of policy, to direct its resources towards the aid of the Civil Community. It is recognised that long-term policies cannot be effective unless and until the Military have the goodwill of the Civil Community. Thus Military Aid to the Civil Community (M.A.C.C.) is described and the role of the S.A.S. within such policy is discussed with particular reference to the ethics and practice of limited medical help.

The status of the " Medical Aide" is the key to the effectiveness of his deployment. Such status depends upon the proper development and control of these soldiers to whom much medical responsibility is delegated.

The S.A.S. "Medical Aide" requires a programme of initial training and regular continuation training in which there is a strong emphasis both upon exposure to supervised clinical experience and subsequent assessment under operational conditions. Only in this way can control be effective.

\section{Introduction}

The substance of this paper relates to the author's experience as a Medical Officer with the Special Air Service between 1964 and 1967. The observations which follow thus have particular application to the sort of problems encountered by small groups of men living and moving in isolated areas.

Although comment is based upon personal experience during this three-year period, 
it is felt that the lessons to be learned from situations in which survival efforts may become necessary are not limited to the circumstances from which they are drawn.

Survival is more than just the maintenance of a tenuous existence against the vagaries of the elements, and recovery from the threat of disaster can rarely claim to have a dependance upon the sort of luck of such a man as Lewis Galdy, whose epitaph records that:-

"He' was swallowed up in the great earthquake in the island of Jamaica in 1692 but thrown into the sea by a second shock and then kept swimming until rescued by boat!"

Survival is itself but one phase in the continued function of an individual or of a group of individuals against the contingencies of unexpected circumstances. If we are to be effective in planning for survival we must learn to anticipate the unexpected.

We may do this upon the basis of our previous personal experience. In wider circumstances man learns to harness his faculty of curiosity-the ability to pose a question and pursue an answer to it-within the discipline of the method we call science. Although science cannot presume to measure luck, it can measure the mathematical concept of probability which we call chance.

There is too, a usefulness in argument by analogy. It is in this last respect that this paper is written in the hope that what has been observed within the range of S.A.S. activities will be of interest to a wider audience.

As doctors whose common concern is to safeguard the health of those who are at risk from the occupations they pursue, we find a succint statement of the control of our environment in the priorities enumerated by Stead (1960):-

a. Insuring the elements of simple survival.

b. Prevention of disease and poisoning.

c. Maintaining an environment suited to man's efficient performance.

d. Preservation of comfort and the enjoyment of living.

This paper examines the medical capabilities of the S.A.S. with particular reference to the training and deployment of its medical auxiliaries. The role of these men is to provide medical support for small groups engaged in operations in isolated areas in which immediate medical help is otherwise unobtainable.

In order to achieve this aim it is intended: First, to identify the hazards to health which by the nature of their occupation, are particularly associated with S.A.S. men. Second, to demonstrate that there are special requirements for the medical care of isolated S.A.S. formations which are best met by a scheme of medical training designed specifically for S.A.S. personnel. Third, to describe the medical training policies for the S.A.S. which have evolved to meet these needs.

\section{Historical background}

\section{Development and role of the S.A.S.}

"We shall see the development of enterprises carried out by chosen men, acting in crews and producing, in a few moments, at a time and place unforeseen, shattering results."

M. Paul Valery (quoted in de Gaulle's War Memoirs) 
War in the Western desert began on 10 June 1940 with the alignment of Italy to the Axis Forces. Two months later the Long Range Desert Group (L.R.D.G.) was raised with the primary task of mounting deep reconnaissance and surveillance missions.

Subsequently the S.A.S. originated to undertake an aggressive role of harassment upon the enemy's line of communication. By a close adoption of survival and navigation methods evolved by L.R.D.G., the S.A.S. was to achieve a noteworthy disruption of enemy movement and inflict heavy losses upon enemy air-power. A total exceeding 250 aircraft was destroyed during S.A.S. raids on desert airfields (Cowles 1958).

With the invasion of Allied Armies into Italy and later Western Europe the S.A.S. increasingly adopted parachuting as the means of clandestine entry into occupied territory. It was during this phase that a new dimension came into S.A.S. methods, that is, the raising, training and co-operation with guerilla units in enemy-dominated territory (Harrison 1957). For the S.A.S. to function in the European theatre, their success now depended not so much upon survival against the elements as liaison with the indigenous population whose ravaged countryside had become the arena of opposed forces bent on massive and sometimes indiscriminate destruction. If in the desert, toughness had been a pre-requisite to combat, now in Europe the call was for tact, a peculiar if somewhat robust acquisite which the British Tommy seemed to have. A tact even so that was just a preface to combat and no better measure of the effectiveness of the S.A.S. in these times can be found than the following enthusiastic rhetoric:-

"Captured S.A.S. troops must be handed over at once to the nearest Gestapo unit . . . these men are very dangerous, and the presence of S.A.S. troops in any area must be immediately reported . . . they must be ruthlessly exterminated ",

Adolf Hitler

\section{Selection of S.A.S. personnel}

The S.A.S. today is required to operate in small parties in enemy dominated territory and it is evident that operations of this nature demand men of high morale and physical reliability.

Selection into the S.A.S. from those who volunteer is aimed at discovering an individual's qualities of adaptability to military circumstances (Fig. 1). The suitability of each candidate is appraised by the consistency of his reaction to stressful situations when self-discipline, humour, confidence and determination come to the fore.

The selection process requires a greater expenditure of physical energy than is normally called for in military training and is beyond the capacity of the majority who have made no preparation for it. As a guide, anyone would fail who was unable to navigate alone across 45 miles of unfamiliar mountainous terrain carrying his bergen (weighing 45 pounds) and a weapon within a time limit of twenty-four hours.

On successful completion of the selection procedure and following a further period of probation, the applicant reverts to the rank of private soldier (an S.A.S. Trooper) This probationary period extends over one year and only 15 per cent of all volunteers are eventually accepted into the S.A.S. (Hardy 1970).

\section{Employment within the S.A.S.}

The S.A.S. module is the four-man patrol (Fig. 2). The size of this group is felt to be the minimum consistent with independent deployment. By appropriate logistic 


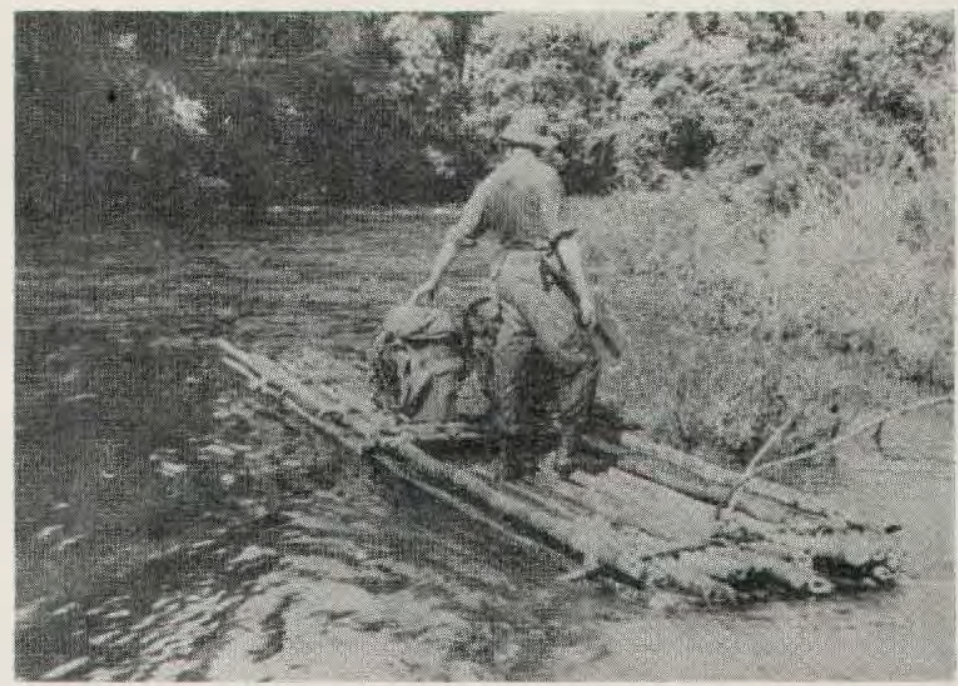

Fig. 1. An improvised raft. This method of travel is particularly vulnerable to ambush and is rarely used.

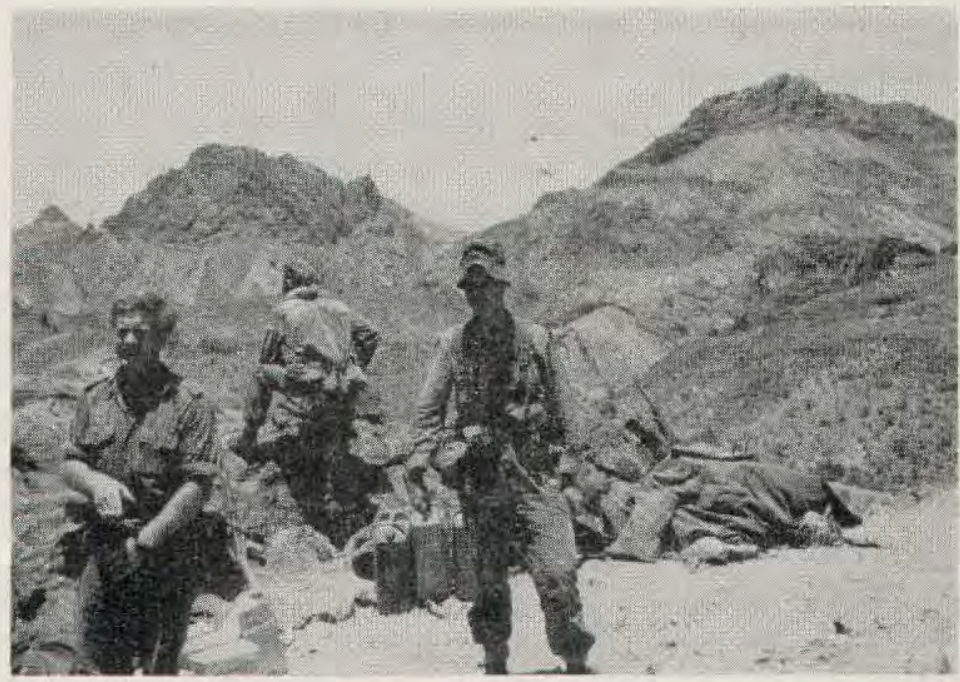

Fig. 2. S.A.S. patrol in the Radfan Mountains, South Arabia.

support such a unit can be maintained in isolation for many weeks and sometimes several months at a time.

Varying individual skills are necessary to facilitate the free-ranging operations of such small formations and paramount of these is radio-telegraphy for it is by this means the contact is maintained with field headquarters. Hardly less important in the maintensnce of military efficiency where prolonged human endurance is a factor, is the need for medical "know-how" within the patrol.

During the first year, the selected recruit undertakes training for basic S.A.S. skills. He is then allocated to a four-man patrol which in turn is part of a larger administ- 
rative unit, the Squadron. Because of its larger size, the functions of an autonomous Squadron differ from those of a four-man patrol. Thus further types of skill are required of an S.A.S. Trooper during his tour with a Squadron.

In this way an individual might be deployed concurrently (depending upon his aptitude) as say a linquist and radio operator; or as a medical auxiliary and frogman; or as a demolition expert and rock climber.

All are parachutists.

All are capable swimmers.

All are skilled in unarmed combat.

All have experienced extensive periods of individual survival training in jungle, desert and sub-arctic conditions.

It is not easy to portray the abilities and responsibilities of these men in a few words yet it would be fair comment to represent the average S.A.S. Trooper as a man selected to respond favourably to the ardous stresses of isolated deployment against hostile forces in inhospitable environments; and who, from the viewpoint of military effectiveness can exhibit a potential for a certain degree of technical versatility.

\section{Medical aspects of combat survival for S.A.S. formations}

\section{Character of the S.A.S. Trooper}

The following observation has been recently recorded on a group of S.A.S. Troopers (Colquhoun 1970) who were flown from the United Kingdom in an easterly direction to North Malaya, resulting in a time-zone shift of seven and a half hours.

"The subjects ... were 40 young (mean age 26.9 years) enlisted men who volunteered for the study. They were of an exceptionally high degree of physical fitness, and were accustomed to making journeys of the kind undertaken in the experiment. Their average intelligence was in the "bright normal " range; personality assessments showed them to be notably more introverted than typical service groups, and to differ significantly from the normal population in terms of tendencies towards the " poles " of the following factors in Cattell's 16 P.F. test: expediency; shyness; suspiciousness; forthrightness; self-sufficiency and high anxiety."

It is such men who, as students, are the raw material for training programmes in S.A.S. skills. These skills include that of the medical auxiliary which is to be described.

The configuration is that of a young man:

a. Whose intelligence is capable of absorbing relevant but limited medical training.

b. Whose aptitude enables him to put that training into practice.

c. Whose physical courage will ensure that he is not found wanting in combat effectiveness.

\section{Morale in perspective}

Military success depends however upon more than the raw material of well-led manpower. Among the more tangible risks to the health of an individual and the outcome of any military mission is the potential incidence of disease and non-battle casualties. 
A report on Accident Prevention (Royal College of Surgeons 1963) stressed "the over-riding importance of morale", yet it is misleading to conclude that toughness alone is a sufficient pre-requisite for the activities of men who must live and move across lonely places. We may note that the journalist allows himself to marvel over the " superhuman " qualities attributed to the lone survivor of an abortive adventure in the Mont Blanc Massif (The Times 1971). His companion, however, died and the tragic remnants of his expedition were extricated at considerable risk to those called upon to effect a rescue. The late Wilfred Noyce (1962) points out that when a man is incapacitated it is not just himself but the whole group that is endangered.

\section{Factors in human endurance}

Johnson (1968) enumerates human parameters additional to personal indefatigability which, in circumstances of isolation may determine the ability of a small group to survive - and it might be added, to remain a viable military force.

These have been re-structured to enhance their relevance to this paper and are shown here as a mnemonic of six basic principles.

$H$ Preliminary state of Health. a. Physical constitution and degree of fitness. b. Extent of fatigue. c. Presence of ill-health or injury.

$E$ Survival Equipment and rations.

A Acclimatisation to the climatic environment.

$L \quad$ Leadership, morale and personal composure.

$T$ Appropriate Training, previous experience and contingency planning.

$H$ Striving towards a maintenance of the military aim, that is Harassment of the enemy.

\section{Hazards to health during S.A.S. operations}

Hazards to health during S.A.S. operations (which as already pointed out are most notable for their isolation) arise from four sources.

a. Casualties arising by mis-chance-Injuries due to non-enemy action, appendicitis, venomous animals.

b. Accidents arising from adverse environmental circumstances-Underwater accidents, cold injury, heat illness.

c. Infective disorders which reflect the sanitary environment to which the soldier is exposed by casual contact with primitive native communities-Malaria, amoebiasis, louse infestation.

d. Zoonoses, in which (usually jungle) fauna serve as a reservoir of diseaseLeptospirosis, scrub typhus, dengue.

\section{Sickness patterns in the S.A.S.}

In order to obtain an estimate of the type and extent of injuries and illnesses which may confront an S.A.S. patrol, hospital admissions of S.A.S. personnel for the years 1959 to 1968 were analysed by cause of admission and a comparison made with the British Army data.

An admission is defined as a case staying in a civil or military medical unit over 48 hours and thus does not truly record the total disease and injury experience. 
Figures for the S.A.S. population at risk were available only as a World-Wide total for "All Theatres" and not for separate military Commands in overseas theatres. Whilst there is some loss of precision in using this figure as the denominator it is felt that the resulting calculations do give a fair indication of S.A.S. admission rates (in fact an S.A.S. Trooper might expect to serve some two-thirds of his tour with the unit engaged upon training or operational commitments outside the United Kingdom).

Since the S.A.S. population at risk was only known for a World-Wide figure, comparision with the British Army in separate Commands for individual years was made by expressing the number of admissions to each diagnostic category as a percentage of "all admissions", to give a distribution of proportional morbidity.

The number of S.A.S. admissions in the separate years was found to be too small for comparison with the British Army to be meaningful and the data were consequently combined to give proportional morbidity distributions for the period 1959 to 1966 .

\section{All theatres}

Proportional morbidity distributions for "All Theatres", 1959 to 1966, were calculated for both the British Army and the S.A.S. and are shown in Fig. 3. To summarise Fig. 3.

a. Injury rates in the S.A.S. are higher than those for the British Army.

b. S.A.S. have much higher rates for malaria (S.A.S. admission rates for fevers other than malaria were very high in 1964 and 1965, but otherwise are not very different to the British Army rates).

c. S.A.S. have much higher rates for gastro-intestinal disease. This is probably a fair indication of the poor sanitary environment to which these men are sometimes subject. They include the following-Food poisoning, helminthiașis, amoebiasis, sprue.

d. S.A.S: admission rates are lower for tonsilitis, influenza and common cold.

\section{United Kingdom and Far East Land Forces comparisons}

It might be supposed that the differences which are apparent between "All Theatres" and United Kingdom (U.K.) for the British Ármy would be reflected by similar changes for S.A.S. However, that this is not always the case is shown by comparison of Figs. 3 and 4.

Admissions for malaria were proportionally greater in the S.A.S. than in the British Army in the Far East Land Forces (FARELF) Command-a feature which became even more distinct in the U.K. where S.A.S. experience of " imported malaria " (that is, infection acquired outside the area where it has been found (Bruce-Chwatt 1971)), is clearly illustrated.

Perhaps not unexpectedly fevers other than malaria form a large proportion of admissions in the FARELF Command with S.A.S. having proportionately the larger experience (Fig. 5). However, this is reversed in the U.K. where the proportion of admissions for the British Army exceeds that of the S.A.S.

Fevers present as malaise. In the absence of any facility for ancillary investigations this will represent the diagnostic problem which faces the S.A.S. Here fevers include, for the purpose of comparision with the British Army, the following:- 


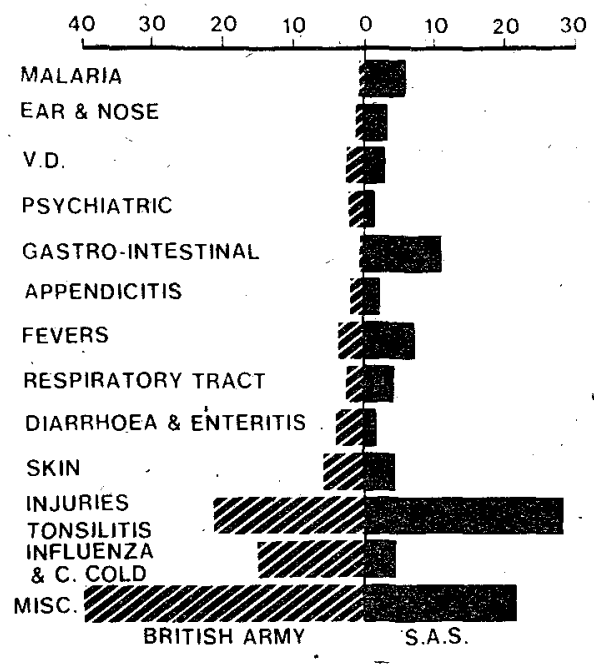

Fig. 3. In all theatres

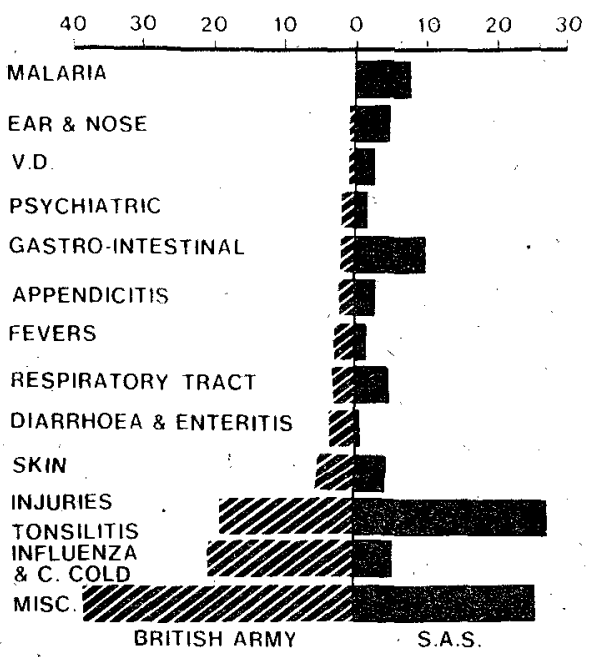

Fig. 4. In the United Kingdom.
Comparison between the S.A.S. and the British Army of percentage distributions of causes of admission to medical units for the years 1959 to 1966 .

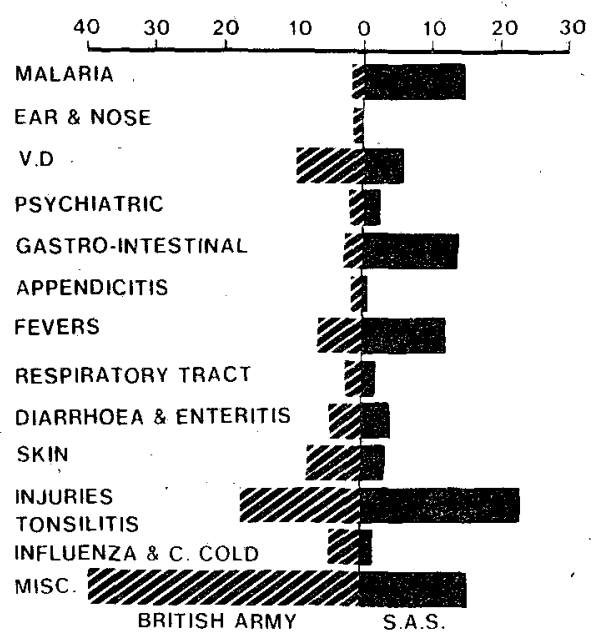

Fig. 5. In the Far East Land Forces

Fevers likely to arise in U.K.-Rubella (German measles). Infectious Mononucleosis (glandular fever). Infectious Hepatitis (epidemic jaundice). Scarlet Fever. Varicella (chickenpox). Measles. Infectious Parotitis (mumps).

Tropical fevers-Pyrexia of unknown origin. Enteric Fever. Acute Infective Encephalitis. Rickettsial diseases (such as scrub typhus). Leptospirosis: Dengue.

A greater difference in the proportion of admissions for Tonsilitis, Influenza and the Common Cold was seen with the British Army between FARELF and U.K. than with the S.A.S.

Although certain S.A.S. risks to health are demonstrated by an examination of admission rates, it is important to bear in mind that the greater hazard to S.A.S. is 
not so much a different prevelance of disease to that of the British Army as a whole, but the fact that their isolation may dictate that they fend for themselves.

The S.A.S. figures represent those broad categories of ill-health and injury which the S.A.S. may be required to deal with in a conservative manner until such time as recovery, or casualty evacuation or death occur.

\section{The need for comprehensive medical training}

\section{The S.A.S. need for medical knowledge}

The military advantages of small groups of highly trained men arise from the general characteristics of decentralisation, concentration of skilled effort, mobility, concealment and so forth. However, the operational deployment of these formations creates increasing problems of logistic support and the Medical Officer is faced with the prospect of long-term separation from the men for whose health he is ultimately responsible.

The varied roles upon which S.A.S. are employed usually involve work in isolated areas and communities in which communications are tenuous. The S.A.S. are therefore expected to function in circumstances where there is no provision for medical support other than what they are able to undertake for themselves.

It is often seen in the history of those groups which are organised to anticipate the changing requirements for new tactics in war, that their neater tricks are first noticed as a "fait accompli" not only by the enemy but also by their own command. That is, that some techniques of combat have been devised on the battle field by the men on the ground, Not a few S.A.S. concepts have come from such empirical beginnings, implemented by those whose immediate circumstances have dictated a need for action. It was probably in this manner that the S.A.S. came to appreciate the inclusion of a competent medical auxiliary in even their smallest formations. Thus by virtue of the tasks of the S.A.S. the requirements of training for a specific medical capability considerably differs from that of the conventionally trained medicalas sistant in other arms.

\section{Preventive measures, health education and training}

The reduction of morbidity on long-range sorties of S.A.S. formations resolve into a co-ordinated three-point programme as follows:-

a. A deliberate effort towards the full implementation' of established principles of military preventive medicine. Such matters are vital. Routine procedures such as immunisation schedules, malaria prophylaxis, water discipline, control of sanitation, must not be taken for granted and are largely a mattèr of competent administration. It may be applicable therefore to recall Sir Thomas Legge's. (appointed in 1898 as the first Medical Inspector of Factories) well-known aphorism in this connection:

"Unless and until the employer has done everything-and everything means a good deal-the workman can do next to nothing to protect himself, although he is naturally willing enough to do his share".

b. The initial education of all recruits selected into the S.A.S. is given scope to produce a Trooper who is well-informed on health hazards and thus better equipped in matters affecting self-care and morale. Thirty hours of instruction time are allocated to this programme. 
S.A.S. officers also attend this initial training cadre and as a result are more able to appreciate the capabilities and limitations of S.A.S. medically trained personnel deployed under their command.

c. The benefits to health, safety and morale which accrue with the inclusion of $a$ medically-skilled Trooper within S.A.S. patrols demonstrate how health problems of particular concern to isolated groups can be tackled. His presence provides a system of immediate medical care to.meet the needs of small-party military operations when conventional medical assistance is not available.

\section{Responsibility for the medical training of the S.A.S.}

The purpose of training S.A.S. personnel in a medical capacity is to produce men with limited qualifications in a minimum amount of time, to perform limited duties as safely as possible- The trainee must learn what he can do and of equal importance, what he cannot do (W.H.O. 1968).

It is in view of the technical nature of advanced medical training for S.A.S. that the implementation of training policies is delegated to the Medical Officer and it is the doctor who thus undertakes responsibility for the training, development and control of S.A.S. medical personnel.

Continuation training is given with the purpose of developing the Trooper's limited medical skill by increasing his competence in what skills he already possesses rather than extending the range of techniques he is taught.

Where motivation is of the highest order (as in the S.A.S.) further medical training should not, in the author's view, be undertaken with the purpose of either advancing promotion or as an incentive to increased pay. The Trooper is primarily a member of the S.A.S. patrol and only secondarily may possess skill as a medical auxiliary. The essence of an S.A.S. qualification for any skill lies in the competence of the Trooper to perform under operational conditions.

It is therefore difficult to conceive that responsibility for S.A.S. medical training could be effective if undertaken by one or several training establishments which were closely linked, not only with the formulation of S.A.S. policy, but also closely associated with responsibility for the health of the S.A.S. under operational conditions.

\section{The need for a standard qualification}

Until the time of the Borneo Campaign in the mid sixties a three-tier system for rating S.A.S. medically trained personnel was operating. At that time it was felt that the distinctions drawn by the grading system which had evolved were more misleading than useful, thus:

In Grade 3 it was possible only to expect a competent standard for first-aid.

In Grade 2 it was difficult to agree upon a standard of proficiency in view of the variability for the periods for hospital attachment.

It was mostly in Grade 1 that misunderstanding might have arisen, since Grade I S.A.S. was apparently graduating from the same class as the United States (U.S.) Special Forces "Medical Aidman". In order to appreciate that this was not the case, the U.S. Army Field Medical Assistant syllabus was examined and a comparison made between the American and his British counterpart which is summarised below. 


\section{Contrasts with U.S. Special Forces}

a. The time available for training is different: United States Medical Aidmen are firstly required to undertake a nine-months clinical specialists course at the end of which they graduate as U.S. Army Field Medical Assistants.

b. The student numbers are disproportionate: The U.S. Special Forces are able to draw their trainees from the ranks of men newly drafted into the Medical Corps, whereas the S.A.S. is a very small group by comparison. The staffing and organisation of a training establishment is therefore more readily justified in the American situation, where courses are running continuously.

c. The admission requirements of general education are different: Most American Medical Aidmen are drafted College graduates in subjects allied to basic medical sciences.

d. The role is different: American Medical Aidmen may be required to organise and operate a dispensary serving a local native community. In this capacity, a considerable knowledge of therapeutics is required.

e. Professional recognition is different. The American Medical Aidman is a graduate of a recognised U.S. Army medical training scheme for auxiliary personnel. The S.A.S. " medic" in his various grades was the product of an informal process of ad hoc attachments of varying periods to hospital. As such he had no status applicable outside the S.A.S. (it transpired that S.A.S. Grade 1 "medics" had been allocated " courtesy" pass grades on completion of their nine weeks at Fort Bragg).

f. The training facility is different: The John F. Kennedy Centre has an establishment for a training staff under the direction of a full-time physician. In contradistinction the training of all S.A.S. medical personnel is undertaken as a part of the duties of the Regimental Medical Officer because no better alternative training is available. S.A.S. medical training is concerned with the speedy training of a limited number of medical auxiliaries. Because only one doctor spends just part of his duties in this project, there is a tendency that each change of Medical Officer may, through inexperience, give rise to an expression of originality by unnecessary modifications to aims and methods which have proved effective.

\section{The "Medical Aide"}

The concept of the "Medical Aide"

It was felt that the traditional military term of "Medical Orderly" whilst being fully adequate to describe the duties of such a person in a conventional force, failed to reflect the nature of responsibility held by medically trained S.A.S. personnel. In 1965 a new term was agreed, that of "Medical Aide".* He was required to be a fully selected and trained S.A.S. Trooper whose special skill was that of providing prompt medical support to his patrol.

"If we want to render a particular combination of ideas permanently in the mind, there is nothing which clinches it like a name specially devoted to express it. When a thing has to be often spoken of, there are more reasons than the saving of time and space for speaking of it in the most concise manner possible.".

John Stuart Mill, 1806-1873

* The term "Medical Aide", never really caught on and has now fallen into disuse. The principle however remains: an S.A.S. man selected and trained as a medical auxiliary. 
Once the duties 'of the "Medical Aide" had been defined, the specific teaching objectives were established to determine the training curriculum.

The objective was not so much to develop the clinical judgement of the trainee as to prepare him for specific and limited duties to be performed correctly and intelligently. The training would be aimed at influencing the trainee's attitudes to duties which characteristically would include limited responsibility for deciding upon the assessment and treatment of patients with only remote supervision by radio.

Objectives for "Medical Aides".

The "Medical Aide" is a fully trained combatant soldier of the Special Air Service whose particular responsibility is the ability to render prompt and adequate medical assistance, namely:

a. Advising his patrol commander upon health hazards in the operational area

(i) Anticipating risks to health by means of a " health appreciation " of his immediate location.

(ii) Studying environmental stresses with regard to combat survival in extremes of terrain and climate: Limitations of a hot climate. Living and moving in cold weather. Water safety. Hazards of shallow water diving. Effects of altitude.

(iii) Community health and he natural history of common endemic diseases as they effect personal discipline.

\section{b. Providing active medical support to his patrol}

(i) Immediate resuscitat:cn procedures: Maintenance of the airway in the unconscious. Emergency tracheostomy. Assisted respiration. Closed chest cardiac massage. Arrest of accessible haemorrhage. Prevention, recognition and treatment of shock.

(ii) General nursing care: This implied full attention to the patient's comfort together with the provision of adequate nutrition and includes observation of the patient's needs and of the overall standard of nursing procedures.

Additionally, general nursing care may include attention to the morale of the patient, the application of a planned regime where some specific therapy has been decided upon, and the instruction of one's colleagues by principle and example.

(iii). Supportive management for surgical emergencies when extrication of a casualty is delayed:

Management of shock, including transfusion technique. Immobilisation of limb injuries, including the application of a Thomas splint. Wound toilet and dressing, including suture technique. Management of burns and mass casualty situations.

Injuries at special sites: The hand. Completion of a traumatic amputation. Conservative management of head, chest and abdominal injuries.

Control of pain with analgesics and local anaesthetic.

(iv) Emergency dental care: Recognition and treatment of oral infection. Emergency first aid for maxillo-facial injuries. Preparation and application of temporary fillings. Control of haemorrhage from tooth socket (Note that instruction in the extraction of teeth would contravene Section 34 of the Dentists Act 1957).

(v) Recognition and management of acute medical conditions: History and physical examination of a patient. Contingencies of climate. 
Management of undetermined fevers with particular reference to: Arbo-viruses. Leptospirosis. Malaria. Scrub Typhus.

Snake bite drill. Allergic emergencies. Conservative management of acute abdominal conditions. Diarrhoea and Enteritis. Management of psychiatric battle casualties.

Elementary knowledge of specific drugs, for example: Analgesics. Antibiotics. Sulphonamides. Antihistamines.

(v) Familiarisation with the Medical Pack: Dressings. Drugs. Instruments.

(vii) Use of radio telegraphy to facilitate the following: Asking for advice. Asking for assistance, for example, reinforcement by a crash rescue team. Asking for casualty evacuation.

(viii) The "Medical Aide" has received appropriate training in the promotion, protection and restoration of health (including the recognition and treatment of common diseases).

He has clearly defined duties and is deployed by the Special Air Service under the supervision and guidance of the Regimental Medical Officer. The "Medical Aide" will never undertake treatment unless directed by a doctor except on operational deployment when circumstances dictate that a doctor is not available.

c. Offering within his ability and in consonance with Command Policy, limited medical assistance to ihe indigenous community

(i) Welfare assistance to an underprivileged community is nowadays often referred to as part of a " hearts and minds" campaign.

(ii) The medical aspects of "hearts and minds" cannot lightly be undertaken. Command medical services need to be fully briefed as to the indication for, and intentions to pursue, such a policy. There must be particular concern that the "Medical Aide " does not lack a clear directive should his role include such work in any particular mission. He must be protected from being placed in a position for which his training is inadequate.

(iii) Command policy and planning must be concerned with a genuine attempt to offer medical advice and aid where there is a need in an underprivileged community. A difficult problem is that of continuation of treatment in chronic and endemic disease. This can only be met effectively by integration with or if necessary, the establishment of civilian dispensaries.

(iv) Where such facilities and resources do not exist the "Medical Aide" can be justifiably deployed on strictly humanitarian criteria, to help when he can, where he can, whilst he can.

(v) Emergency midwifery: The purpose is to train the "Medical Aide" at least to the competence of a well-trained ambulance driver in this respect."

The author had felt it to be wrong to place S.A.S. " Medical Aides" in a situation where they might be unable to recognise the more common disorders associated with pregnancy and childbirth.

The "Medical Aide's" awareness of the abnormal in such events has sometimes saved lives by the simple expedient of reporting the abnormality: Ante-natal care. Complications of pregnancy. Pre-natal emergencies. The normal delivery. Breech deliveries. Post-partum haemorrhage. 
(vi) Pediatric emergencies: Asphyxia at birth. Fits in babies. Exposure in babies. Gastro-enteritis in infants. Pneumonia. Heat casualties.

(vii) Field hygiene: Water discipline. Sanitary discipline. Anti-malarial discipline. Rodent control.

\section{The training programme}

The measure of effectiveness for any system of medical training designed to meet the S.A.S. need must be assessed alongside the overall policies and tasks which confront the S.A.S. Responsibility for the deployment of the "Medical Aide" rests with the Commanding Officer, and medical training is integrated within the overall training policy and programmes of the Regiment.

The programme is based upon an intensive four-week course consisting of formal teaching sessions, tutorials, visits, demonstrations and practical classes. The aim is to teach specific principles of medical practice and where a technique is being learnt every opportunity must be taken to train the "Medical Aide" by standard methods of instruction.

Visual aids are used extensively in accordance with the principles and techniques of teaching practice.

The "Medical Aide" must compile under close supervision, a complete set of notes for later reference under field conditions. Ideally, a manual should be written for him (until this is produced, the best alternative is undoubtedly the Royal Geographical Society's guide to the prevention, diagnosis and treatment for explorers written by Colonel Jim.Adam, O.B.E., Ph.D., M.B., late R.A.M.C. 1966).

Frequent evaluations of the trainee's progress are essential. Several purposes are thus served:

(i) The effectiveness of the training programme can be judged.

(ii) With prompt feed-back, the examination itself provides a useful means of further learning for the student.

(iii) The developing competence of the trainee is assessed.

The four-week course is a preliminary to the attachment of the "Medical Aide" to accident departments in a number of selected civilian hospitals. The minimum period for this attachment should be four weeks and experience has shown that a lesser period than this is seldom of much benefit.

Each hospital needs to be given the objectives for "Medical Aides" as a guide on the scope they are asked to teach. The pattern is of closely supervised tuition arising as events occur within the department. A check-list is sent with each trainee, to allow the supervising physician to record the trainee's experience.

The Regimental Medical Officer maintains contact with these hospitals. The type of teaching which the participating hospitals give, the clinical material which they demonstrate and the principles underlying casualty procedures are discussed with the Directors of Casualty Departments. Merely sending a "Medical Aide" away on an attachment to a hospital where tuition is not integrated to his needs is obviously not satisfactory. What is taught during the attachment should as far as possible, be specified. Observation and demonstration alone are insufficient. Active duties and full rotas are 
essential if the "Medical Aide" is to prove confident and capable to deal with the situations which may confront him in combat.

The effect of the hospital attachment scheme in its contribution to the training of "Medical Aides" bears a close relationship to the realisation by the hospital staff of the subsequent role and deployment of their soldier pupils. Their personal interest is vital.

The benefits and limitations of such attachments are no longer matters for conjecture and speculation. The measure must be gauged by the capabilities of a "Medical Aide" under operational conditions.

\section{Military aid to the civil community (M.A.C.C.)}

\section{Definition of hearts and minds (Frazer-Allen 1968)}

Recent events have demonstrated that success in Counter Insurgency situations cannot be achieved by military victories alone. An essential factor is what has become known as the battle for the "Hearts and Minds" of a population (either urban or rural) subjected to subversion and inflation. It had become apparent that the mere provision of direct aid in the form of finance or equipment was often actually counterproductive and that the real requirement was for security in the face of threats and for technical skill and advice. In this way it is hoped to provide people whose livelihoods had become precariously placed, with as many as possible of the essential facilities and resources of normal life.

\section{M.A.C.C. objectives}

The February 1968 Defence White Paper examined the question of military aid to the civil community and concluded that " we are preparing to improve the arrangements for helping the civil community as a normal Service activity in so far as this is compatible with peacetime training".

Some nations now specially "rain servicemen for an M.A.C.C. role. Examples of this policy are to be seen in U.S. Military Aid and Advisory Groups, or the Civic Action Groups of the Phillipine and Korean Republics recently deployed in South Viet-Nam.

Tasks of M.A.C.C. resolve into three main functions; those of disaster relief, assistance by specialists, and peace-keeping operations, examples are:

(a) The Armed Services have the vital characteristic of a command structure with communication systems directing mobile reserves. They are thus able to offer general assistance in local or national disaster relief as: The relief of Belize following hurricane Hattie. Aberfan. "Torrey Canyon". Numerous examples of flood, earthquake and storm relief.

(b) Specialist assistance can be given, often on a long-term basis: Survey and Construction projects undertaken by engineer task forces. Field Hospitals. Civilian patients treated in static Army hospitals.

(c) Peace-keeping operations involving Internal Security in conjunction with Civic action: "Hearts and Minds" policy in Borneo. Deployment of troops in Northern Ireland.

Two principles must consistently obtain in ensuring that these efforts achieve their objective: 
Firstly. Military help must only be given where requested by a civic community (Fig. 6). It cannot be imposed.

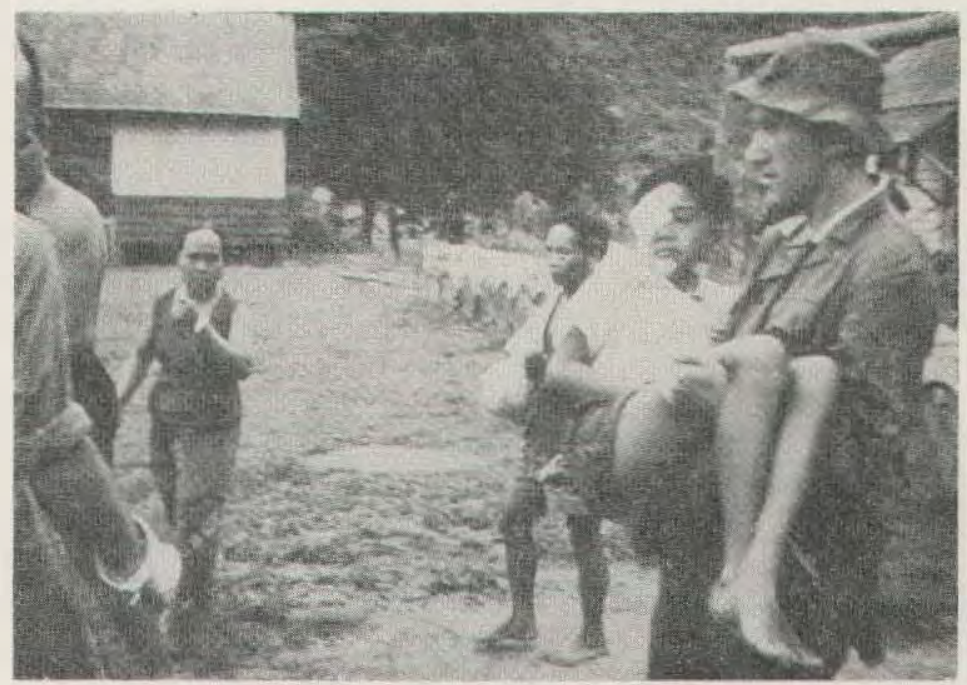

Fig. 6. S.A.S. doctor summoned by radio to assist "Medical Aide".

This little boy had been involved in a hunting accident and was evacuated by helicopter.

Secondly. The aim will only be realised when the public in that community are convinced of its intrinsic value.

\section{The Borneo campaign 1963-1966}

"When the House thinks of the tragedy that could have fallen on a whole corner of a Continent if we had not been able to hold the situation and bring it to a successful termination, it will be appreciated that in the history books it will be recorded as one of the most efficient uses of military force in the history of the world."

The Secretary of State for Defence House of Commons, 27 November 1967

It had been the express aim of the Director of Operations, Borneo, to prevent cross-border incursions from Indonesia escalating into open warfare. This primary aim was achieved by a vigorous pursuit of parallel military and civil objectives:

(a) The battle of the jungle: " Our objective was to dominate and own the jungle ... week in, week out, day and night. There was no galloping over the jungle canopy in helicopters ... The sure way to beat a guerilla is to operate more quietly, smoke less and talk less."

(b) The civil objective: "It was necessary to win the psychological battle in the Kampongs. It was because we won the hearts and minds of these people that ... victory was ours with a loss of life which was less over three years than the slaughter on the roads in Britain over a single Bank Holiday "... . 
It is recorded that the political-military co-operation took place at every level. A unified command of civil administration, civil police and the armed services set the policy which was to be given practical effect by the soldier in the Kampong and Jungle.

The S.A.S. were employed throughout the Borneo Campaign and in summary the following quote from the Director of Operations is relevant:

"We set out ... to win the local people's trust, confidence and respect. We set out to speak their language and respect their customs and religion.

We sent small highly trained Special Air Service patrols to live and work among them (Fig. 7), to protect them and share their danger, to get to know them and gain their confidence.

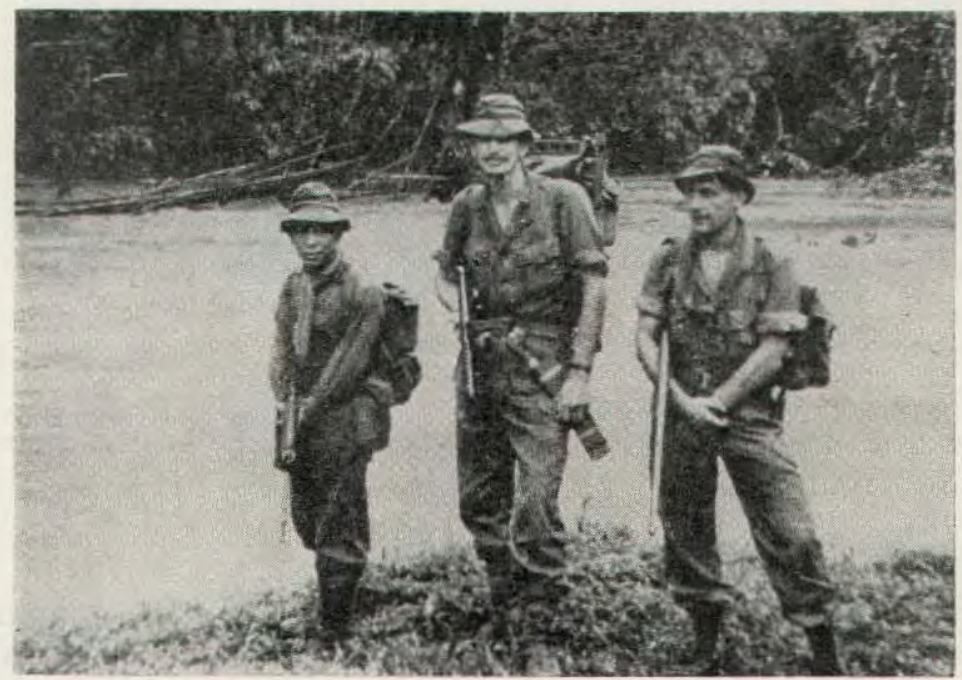

Fig. 7. S.A.S. officer and radio operator with Iban guide in North Borneo jungle.

These troops were as friendly, understanding and patient to the villagers as they were tough and ruthless in the jungle.

We sought to give the villagers a feeling of security by day and night, through the presence of phantom patrols."

\section{Discussion}

Judging the performance of the "Medical Aide"

In his appraisal of the attainments and short fallings of his medical team, the Regimental Medical Officer is involved in subjective judgements at times based upon indirect or incomplete evidence. Nevertheless it is important that he has some means of measuring the performance of his men. To be effective in this he will need to know the background which his men are deployed. He will need to be the confidant of his Commanding Officer, and he will need to know something of the skill of soldiering in a survival situation. 


\section{The status of the "Medical Aide"}

"I delegate-but I don't let go!"

Director, U.S. Naval Arctic Research Laboratory, Alaska.

The development of "Medical Aides" should not be thought of in terms of the creation of "mini-doctors" At the least such a term is misleading to those responsible for the deployment of these men. Nor should confusion arise that their intensive training entails a lowering of medical or nursing or first-aid educational standards.

The concept of the "Medical Aide" cannot be construed as in any sense to imply a professional qualification. He does not compare with a midwife or nurse or pharmacist. Such professions have defined responsibilities within their sphere of service but have no authority to make a diagnosis or prescribe treatment (W.H.O. 1966).

The status of the "Medical Aide" needs to be carefully defined and understood not only by those responsible for his training and deployment but also by R.A.M.C. officers who may be asked to offer guidance by radio.

Only certain functions are delegated to the "Medical Aide": he becomes in effect, the eyes and ears of his Medical Officer.

\section{The military value of the "Medical Aide"}

It is stressed that "Medical Aide" training must reflect a constant relationship to the immediate and future operational needs of the S.A.S. Training objectives must be re-evaluated continuously to allow up-dating of requirements as circumstances and commitments change.

Thus, the "Medical Aide" is selected on his resilience to survive and capacity to operate in adverse conditions. His medical training, status and control must be directed towards sustaining him in isolated circumstances. Training restrictions which do not enhance the military value of the "Medical Aide" must be avoided.

The term "Medical Aide", is used to mean a fully trained S.A.S. soldier:

a. Who has received appropriate medical training.

b. Who can undertake a limited and specified variety of diagnostic assessments, standard treatments and preventive measures.

c. Who is authorised to perform limited functions normally carried out by a doctor, but only when and where a doctor is not available.

d. Who is deployed by the S.A.S. under the advice and guidance of an R.A.M.C. Officer to whom he must refer all difficult cases by radio.

\section{Acknowledgements}

I am indebted to Richard Schilling, M.D., D.Sc., F.R.C.P., D.P.H., D.I.H., Professor of Occupational Health, London University, for his encouragement and permission to submit this paper, based on a dissertation for the M.Sc. (Occupational Medicine). A copy of this is held in the Royal Army Medical College Library.

My thanks are due: to Staff Sergeant R. Tayler, S.R.N., R.A.M.C. without whose abilities and energy the medical training policies might not, during the tour with the Regiment, have been implemented half so well. To W.O. II D. Aldridge, R.A.M.C., 
Corporal R. Garton, R.A.M.C., Mr. G. Hartnup and Miss Joan Walford, A.I.S. in the production of the statistical data. To Dr. Suzette Gauvain for encouragement, counsel and fair criticism, and to Miss Hannelore Ollesch for the meticulous work undertaken in the final preparation of the manuscript.

I acknowledge with thanks permission to quote from the British Army Review as indicated in the text.

\section{REFERENCES}

ADAM, J. M. (1966). A Traveller's Guide to Health. Hodder \& Stoughton. London.

BRUCE-CHWATT, L. J. (1971). Brit med. J. ii, 91.

ColqHuoun, W. P. (1970). Interim Report "Nychthemeral Rhythms and Air Trooping". Ministry of Defence, A.M.D. Report 165/69.

Cowles, V. (1958) Phantom Major. Hard back-Companion Book Club, Odhams Press Ltd., Watford. Paper back-Fontana Books, Collins Clear Type Press, London.

Frazer-Allen, M. (1968). British Army Review No. 29.

HARDY, T. (1970). Personal communication.

HarRison, D. I. (1957). These Men are Dangerous. Cassell \& Company Ltd. London.

JOHNSON, R. H. (1953) Brit. med. J. i. 697.

NOYCE, W. (1962. They Survived. Heinemann Books. London.

STEAD, F. M. (1960). Amer. J. publ. Hlth. 50, 312.

WALKER; W., British Army Review No. 32.

Working Party on Accident Prevention and Life Saving Report (1963). Royal College of Surgeons. London.

W.H.O. (1966). Technical Report Series No. 347.

W.H.O. (1968). Technical Report Series No. 385.

\section{R.A.M.C. COURSE PRIZES FOR 1972}

91 D.T.M. \& H. Course

Leishman-Major R. Jeffery, RAAMC Parkes-Major R. Jeffery, RAAMC

Katherine $W e b b-$ Major R. Jeffery, RAAMC

Joseph Fayrer-Major R. Jeffery, RAAMC

\section{Senior Officers' Refresher Course}

Montefiore-Major A. J. Spicer

\section{Postgraduate Medical Officers' Course}

Sidney Herbert-Captain P. M. Brown DeChaumont-Captain P. M. Brown

Ranald Martin-Captain P. R. Bowman

Parkes-Captain D. J. Cave-Bigley Captain M. J. Reilly

Tulloch Memorial-Captain D. A. Curson

J. R. Rees-Captain P. M. Brown

Marshall Webb-Captain A. M. Grieve

\section{Postgraduate Medical Officers' Course}

Sidney Herbert-Captain D. W. Smith DeChaumont -Captain D. N. Wilson

Ranald Martin-Captain P. F. Newman Tulloch Memorial-Captain D. W. Smith

Montefiore-Captain D. W. Smith

Parkes-Captain D. W. Smith

$J$. R. Rees-Captain L. S. Cantlay

Marshall Webb-Captain D. W. Smith 